\title{
Faculty perceptions of the integration of SAP in academic programs
}

\author{
Sam Khoury $^{* a}$, Kouroush Jenab ${ }^{b}$ and Selva Staub $^{c}$
}

\author{
${ }^{a}$ Sam Khoury, East Carolina University \\ 'Selva Staub, Haliç University, Istanbul Turkey

\begin{tabular}{l}
\hline A R T I C L E I N F O \\
\hline Article history: \\
Received October 15, 2011 \\
Accepted 10 March 2012 \\
Available online \\
14 March 2012 \\
\hline Keywords: \\
SAP \\
ERP \\
University Alliance
\end{tabular}

${ }^{b}$ Kouroush Jenab, Education chair, Society of Reliability Engineering-Ottawa

\section{Introduction}

In order to prepare students for challenging careers, academic institutions have integrated and taught software applications. Some of these applications are integrated into one or two courses, while the others are implemented throughout a degree program. Those integrated throughout degree programs immerse students in the applications and reinforce knowledge gained in previous courses. Furthermore, prolonged exposure usually leads to longer retention and improved understanding of the software. Some software applications are relatively easy to implement because they are designed to perform a specific function, such as word processing or computer aided design and can be included in one or two appropriate courses.

In contrast, Enterprise Resource Planning (ERP) applications are designed for a variety of functions that span the entire organization. Since their scope is large, they are more complex, require more training, and are more difficult to implement within degree programs. As a result, faculty members

\footnotetext{
* Corresponding author

E-mail addresses: khourys@ecu.edu (S. Khoury)

C 2012 Growing Science Ltd. All rights reserved. doi: $10.5267 /$ j.msl.2012.03.014
} 
are often reluctant to implement ERPs into their degree programs. Furthermore, academic institutions may not be very receptive to the idea of having to purchase additional hardware and software that can substantially add to the cost of supporting academic programs. Fortunately, software makers firms that develop and distribute ERPs understand that faculty and institutions may be reluctant to implement their products and therefore have implemented tailored training and support programs. These training and support programs provide discounted or free versions of their products to universities in an effort to encourage adoption of their products.

One of these software makers firms is SAP. SAP is a leader in the ERP market with implementations worldwide. According to SAP (SAP, 2011), there are approximately 176,000 customers that rely on their software solutions and services. Their rapid expansion in the ERP market has led to a shortage of skilled SAP technicians, specialists, and programmers. In an effort to expand the SAP workforce and to generate more visibility of their products, SAP has created the SAP UA program. For over a decade, SAP has promoted and integrated its SAP UA program into university degree programs.

SAP is an obvious beneficiary of the SAP UA program. Their products have become more visible to students who will be joining the workforce in the near future. Furthermore, these SAP UAs add to the available skilled workforce by helping expose students to a popular set of software tools used throughout industry. Students also benefit from the University Alliance Program by gaining valuable skills they can use in industry.

Of course, universities also benefit from the SAP UA program. Providing students opportunities to work with the latest software packages enables students to gain valuable skills and allows universities to promote themselves as innovators and leaders in education. As a result, universities are able to show prospective students that they care about preparing students for rewarding and challenging careers.

Although it appears that students, industry, and academic institutions benefit from the SAP UA program, little is known about faculty perceptions of these programs. A review of the literature did not reveal any comprehensive studies of faculty perceptions of these arrangements between the software maker and universities. Therefore, more research is needed to determine how faculty members teaching within these programs of study feel about the SAP UA program's effectiveness, strengths, and weaknesses. Since faculty play an integral role in the success of the SAP UA program, understanding their perceptions of the program is essential.

\section{Literature review}

ERP systems provide numerous benefits for firms (Basu et al., 2004; Garg, 2010; McCombs, 2007; Steven, 2003). According to Davenport et al. (2002), some of these benefits have been identified as improved management and decision making, improved financial management, cycle time reduction, and increased revenues. All of these benefits make ERP systems attractive to corporations. As a result, a shortage of skilled SAP workers dates back to the 1990s when the Year 2000 (Y2K) scare pressured organizations to abandon legacy systems that utilized two-digit year fields (Hawking et al., 2004). These systems were replaced with modern ERP systems such as SAP ERP and as a result, it created the need for more skilled ERP experienced workers.

The ERP boom taken place prior to the Y2K generated numerous studies of ERP implementation. Some of these studies concentrated on ERP maturity and models used to represent different levels of maturity in order to gain a better understanding of ERP implementations (Davenport, 2000; Fraser et al., 2002). Other studies focused on the successes and failures of ERP implementation (Bondarouk \& van Riemsdijk, 2007; Noudoostbeni et al., 2009). These studies attempted to determine the factors that result in successes or failures of ERP implementation. Furthermore, these studies established a connection between these successes and failures to learning theories. 
Much of the stream of studies that centered on learning and implementation of technology focused on the work of (Kolb, 1984) and other experiential learning theorists. According to Bondarouk and van Riemsdijk (2007), it is indicated that over 1,500 studies have carried out based on Kolb' work (1984). These studies have touted that experiential learning is more effective learning. Therefore, academic institutions that employ live software packages such as ERPs in an attempt to ensure that learning takes place through hands-on experience are more able to ensure that learning is retained and more meaningful to those students that will be entering the workforce. It is the experience gained through actual exposure, which leads to meaningful learning (Dixon, 1994). Therefore, academic institutions that have considered the benefits of experiential learning over the past two decades have attempted to integrate ERP software into their curriculum. While some implementations have been successful, many more have not been for various reasons (Antonucci et al., 2004).

Although significant research exists on the study of ERP implementation in industry, little research exists on the study of ERP implementation in academic programs. One of those few studies that have explored the effectiveness of ERP implementations in academic programs is associated with Boykin and Martz (2004). It sets out to determine if the integration of ERP in an academic program will lead to an increased understanding of business processes. In their study, they used a pre and post survey to measure student understanding of business processes. They argued that understanding the business process is more effective than understanding tasks performed by business students. Furthermore, they pointed to significant research, which shows an understanding of processes is more desirable yet lacking in academic institutions. Their findings indicate that an implementation of an ERP, in this case SAP, helps create a better understanding of business processes among students exposed to this integration, as compared to students that were not exposed to SAP.

While there is available research demonstrating that ERP implementation in academic programs adds value to student learning, implementing SAP into academic programs has been challenging for institutions (Corbitt \& Mensching, 2000; Hawking, 2004; McCombs, 2007; Seethamraju, 2007). According to Hawking (2004), these struggles that academic institutions face were outlined. They included issues such as lack of uniform curriculum and faculty training, lack of continuity, and difficulty teaching business processes through labs designed around tasks to be performed in SAP. According to Hawking et al. (2004), numerous changes to SAP's UA have taken place. Some of these changes have resulted in increased opportunities and higher salaries for graduates (Sager et al., 2006).

Since there is substantial literature, which documents the benefits of ERP within organizations but limited research on the integration of ERP within academic programs, this study determines the current state of the SAP UA initiative by surveying SAP UA faculty. Critical goals of this research are to determine whether improvements made to the SAP UA program have increased its effectiveness, and to identify areas of further improvement.

\section{Methodology}

The survey instrument was designed using the Qualtrics ${ }^{\circledR}$ survey design tool and administered online through a password protected site. Invited participants were supplied with a link and password to access the survey. The survey was administered during the fall of 2011 and consisted of a combination of seven Likert scale questions and eleven demographic questions.

An internet and SAP UA portal search was conducted to locate faculty in the SAP UA program. The search resulted in 186 names and email addresses of faculty within the SAP UA. Eleven of the emails were not valid. Therefore, only 175 email addresses were used to invite participants. An opening page to the survey asked faculty to complete the survey if they met the minimum one year experience in the SAP UA program, otherwise they were asked to close the survey without completing it. Several reminders were sent during the survey period. Out of the 175 potential participants, 55 completed the survey resulting in a $31 \%$ response rate. 
Participation in the study was strictly voluntary. Faculty invited to participate in the study were advised that they could refuse to participate at any time during the study. Furthermore, participation in the study was strictly anonymous. Participants could not be identified by taking part in the study, since no identifying data was collected at any time during the study. In order to determine faculty members' perceptions of the SAP UA program, this study attempted to address the following research questions:

- Do faculty members feel the SAP UA program is preparing students for rewarding careers?

- Do faculty members feel the SAP UA program is correctly aligned within their degree programs?

- Do faculty members feel they have the necessary skills to teach the required materials in the SAP UA program?

- Do faculty members feel they have the necessary support from their academic institutions in support of the SAP UA program?

- Do faculty members feel SAP provides the necessary support they need?

- What areas do faculty members feel needs the most attention within the SAP UA program?

- What do faculty members feel are the strengths and weaknesses of the SAP UA program?

- How integrated is the SAP UA program within their degree program?

\section{Limitations}

There are several limitations to this study that are worth noting. One of these limitations was the lack of available contact information that could be used to identify SAP UA faculty. Requests for email addresses placed through the SAP UA regional centers were denied due to privacy concerns despite assurances the survey would be administered anonymously. Therefore, a search of the Internet was performed to identify potential participants and resulted in an available population of 175 possible participants. Since the population is relatively small compared with the total population of UA faculty, the results of this study may not apply to the overall population. A larger population would have produced more accurate results. Further limiting the study was the average response rate of $31 \%$. Although a $31 \%$ response rate is considered normal for surveys where the majority of faculty members are from business schools, a higher response rate would have produced more accurate results.

Another limitation of this study is that it relies strictly on a survey tool to gather data. Although careful survey design and testing attempted to reduce survey bias, unintentional bias may have had an effect on the results of this study. Incorporating other methods such as personal interviews to obtain data for this study may have produced more accurate results.

Furthermore, no method was available to determine the level of experience of SAP UA faculty invited to participate in this study. Therefore, all SAP UA faculty members that were located were invited to participate and asked not to complete the survey if they did not have at least one year of experience as a SAP UA member. In this study, it is assumed that the survey was conducted as instructed without disturbance.

\section{Data analysis}

The designed questioners have been filled out by 55 full-time faculty members within a SAP UA program. Participation in this study was strictly voluntary. Figs 1, 2, and 3 depict the distribution of the participant's gender, age, and the use of SAP in the programs derived from this survey. 


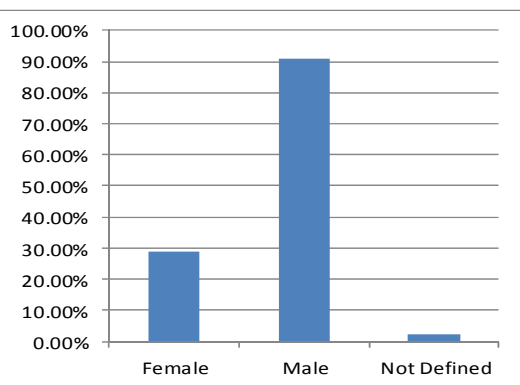

Fig 1. Gender distribution of the participants

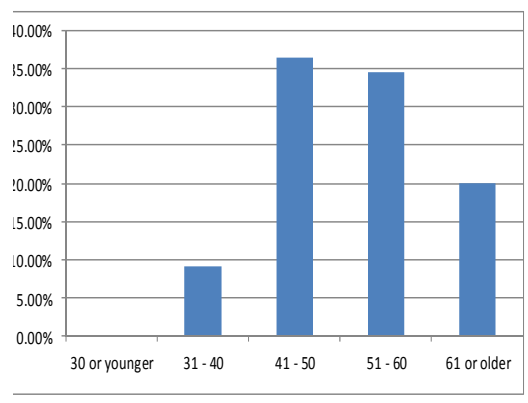

Fig 2. Age distribution of the participants

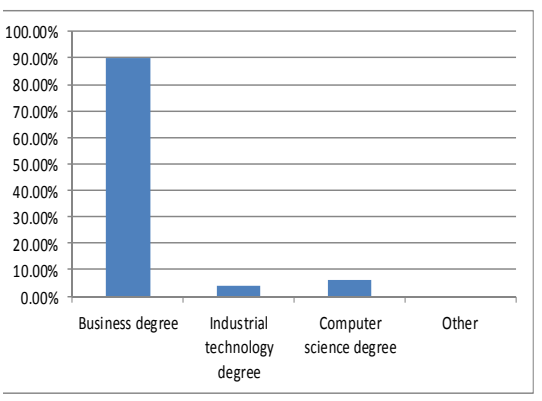

Fig 3. The use of SAP in programs

This study examined the significant factors leading to success in SAP UA programs at the universities while preparing students for careers that involve the use of SAP. These factors are:

- The SAP UA program labs and training modules are correctly aligned within degree $\operatorname{program}(\mathrm{s})$.

- SAP technical skills to teach courses in the SAP UA program.

- The academic institution provides the necessary support to SAP UA program needs to be successful.

- SAP provides the necessary support to the SAP UA program for it to be successful.

At a confidence level $\alpha=5 \%$, performing two-way ANOVA proves that these factors are equally significant in the success of a SAP UA program (P-Value: 0.08). In addition, another design of this experiment proves that the successful implementation of SAP UA program with $\alpha=5 \%$ is strongly dependent on the following factors:

- The academic institution provides the necessary support our SAP University Alliance Program needs to be successful.

- SAP provides the necessary support our SAP University Alliance Program needs to be successful.

- The Computer skills are sufficient to teach in the SAP University Alliance Program.

- Number of courses within the degree program that contain $30 \%$ or more of SAP University Alliance Program content

\section{Conclusions}

Literature pertaining to ERP implementation witnesses that little research exists on the study of ERP implementation in academia. The aim of this study was to analyze faculty members' perception toward the SAP UA program's effectiveness, strengths, and weaknesses. Therefore, a selective survey was performed to identify the significant factors leading to success in the SAP UA programs.

An Internet and SAP UA portal search resulted in locating 175 valid email addresses within the SAP UA. Out of the 175 potential participants, 55 completed the survey resulting in a $31 \%$ response rate. Data analysis showed that the alignment of the training modules, SAP technical skill, institutions' support, and SAP's support are significant factors. Although there are some limitations in this study, they do not have significant effect on the outcomes delineated in Section 6.

In future research, one should study the effectiveness of the SAP UA program on long-term retention of ERP.A comparative analysis between the SAP UA integration approaches in different schools is required in order to identify the best practices that could lead to a unified approach to SAP UA 
integration. Conducting studies to identify not only the variables causing SAP UA failures but also preventive approaches seems important. Also, since the results of this study show the majority, $82 \%$, of respondents were from schools of business, further investigation is required to understanding lack of interest in SAP in other schools such as manufacturing and industrial technology. This may lead to innovative ways to increase available faculty training and standardized curriculum within the SAP UA program. It is noteworthy that $69 \%$ of the respondents noted a need for more faculty training and $45 \%$ noted a need for more standard curriculum. These future studies can help strengthen the SAP UA program and lead to more prepared graduates.

\section{References}

Antonucci, Y. L., Corbitt, G., Stewart, G., \& Harris, A. L. (2004). Enterprise systems education: Where are we? Where are we going? Journal of Information Systems Education, 15(3), 227-234.

Basu, R., Upadhyay, P., \& Dan, P.K. (2011). Factors influencing ERP implementation in Indian SMEs: An empirical analysis. Management Science Letters, 1(2), 89-98.

Bondarouk, T \& van Riemsdijk, M. (2007). Successes and failures of SAP implementation: A learning Perspective. International Journal of Technology and Human Interaction, 3(4), 33-51.

Boykin, R. R. \& Martz, W.M. (2004). The integration of ERP into a logistics curriculum: Applying a systems approach. Journal of Enterprise Information Management, 17(1), 45-55.

Corbitt, G. \& Mensching, J. (2000). Integrating SAP R/3 into a College of Business curriculum: Lessons learned. Information Technology and Management, 1(4), 247-258.

Davenport, T. (2000). Mission critical: Realizing the promise of enterprise systems. Harvard Business School Press.

Davenport, T., Harris, J. \& Cantrel, S. (2002). The Return of Enterprise solutions. Wellesley, MA: Accenture Institute for Higher Performance Business.

Dixon, N. (1994).The organizational learning cycle. London: McGraw-Hill.

Fraser, P., Moultrie, J. \& Gregory M. (2002). The use of maturity models/grids as a tool for assessing product development capability. IEEE Engineering Management Conference. Cambridge.

Garg, P. (2010). Critical success factors for enterprise resource planning implementation in Indian retail industry: An exploratory study. International Journal of Computer Science and Information Security, 8(2), 358-363.

Hawking, P., McCarthy, B., \& Stein, A. (2004). Second wave ERP education. Journal of Information Systems Education, 15(3), 327-332.

Kolb, D.A. (1984). Experiential learning: Experience as the source of learning and development. Englewood Cliffs, NJ: Prentice-Hall.

McCombs, G.B. (2007). A model continuous improvement based ERP applications class. Journal of American Academy of Business, 10(2), 58-64.

Noudoostbeni, A., Yasin, N. M., \& Salarzadeh, H., (2009). To investigate the success and failure factors of ERP implementation within Malaysian Small and Medium Enterprises (SMEs). The International Conference on Information Management and Engineering (ICIME), Kuala Lumpur, Malaysia: IEEE, 157-161.

Sager, J., Mensching, J., Corbitt, G. \& Connolly, J. (2006). Market Power of ERP Education: An Investigative Analysis. Journal of Information Systems Education, 17(2), 151-161.

SAP (2011). SAP customer showcase. Retrieved Nov 13, 2011 from http://www.sap.com/customershowcase/index.epx, 2011.

Seethamraju, R. (2007).Process orientation to business students: Enabling role of enterprise systems in curriculum. Proceedings of the 18th Australasian Conference on Information Systems, 10-12 Dec. Toowomba, Queensland.

Steven, C. P. (2003). Enterprise Resource Planning: A trio of resources. Information Systems management, 20(3), 61-67. 